darin zu erkennen, dass die ärztliche Taxe grundsätzlich aufgelıben worden ist, dass aber Ausnahmen von dieser Regel Seitens der Stadtsregierung für nothwendig gehalten werden. Diese Ausnahmen lassen sich unter dem Gesichtspunkte zusammenfassen, dass besonders denjenigen, die eine ärztliche Belıandlung ohne Entgelt weder beanspruchen können noch wollen, die Möglichkeit gewalırt werde, zu mässigen, ihren Verlältaissen entsprechenden Preisen, derselben theilhaftig zu warden. Zu dieser Kategorie gehören vor Allem die in $\$ 2,2$ genannten hassen, unter sie lässt sich auch leicht $\$ \mathbf{5 4}$ der Konkursordnung subsuıniren. In allen anderen Fällen ist der Arzt nacl diesem Entwurfe frei. Ilat eine vorlserige Vereinbarung nicht stattgefunden, so ist in Process der Richter nicht mehr gezwungen wie früher die Maximaltaxe als Grenze anzunehnen, er wird vielmelır durch den Entwurf auf eine Reihe von Momenten lingewiesen,' welche höhere l'reise rechtfertigen. Der Arzt als Kläger kann eventuell Sachverständige vorschlagen und befindet sich denı Richter gegenüber durchweg in einer ganz anderen Stellung als bisher. Irren wir nicht, so wurde zumeist üluer die unzureichende Maximaltaxe geklagt, die durch den Entwurf heseitigt ist. Auch nach der Annalıme des letzteren werden die Gerichte noch Lnbegreifliches leisten, werden diese Ausnahmstaxe für die Basis ilırer Rechtsprechung lıalten, aber das Gleiclıe würde auch bei einer ahsoluten Abschaffung jeder Taxe eintreten.

Wir möchten, dass die Vereine sich zuvörderst über das Princip schlüssig machten, ob nicht der Staat das Recht hat, für die Kreise in der That einzutreten, für die seine Ausnahmstaxe bestimmt ist, denn die Einzelheiten der letzteren sind kein unantastbares Evangelium.

Den vieleı Vorwürfeı gegenüber aber, welche den Ansätzen des Entwurfes gemacht werden, die wir keinesweges durchweg billigen (Dienstmannstaxe etc.) müssen wir doch benerken, dass sie zum Theil weit über die Preise hinausgehen, z.u deneı die Aerzte sich selbst einzuschätzen pflegen. Wir lıaben niemals ein offenes Wort in dieser Beziehung gescheut und halten es für eitel Lieberlienerri, weın man die thatsächlichen Schätlen immer den Behördeı zuschiebt, statt zn prüfen, in wie weit man selbst die Mitschuld daran trägt. So lange noclı viele Aerzte in Folge ihrer rregenseitigen Concurrenz, liei all dell schönen Redensarten von Standesehre und Collegialitat, sich herablassen als Haus-, Arnien-, Gewerhs-, Vereins-etc. -Aerzte für ilire Leistungen ein Aequivalent selbst zu bedingea, welches unter der bienstmannstaxe steht, darf man sich nicht wundern, weon der Staat davon Act nimmt. Es liesse sich hicrüber und dann üljer manche Vorkommnisse der neueren Zeit, welclıe nicht dafür sprechen, dass der alte humane Sinn der Aerzte sich üherall conservirt hahe, noch viel sagen, wir verzichten heute darauf und erinuern nur noch nut Rohden an das Wort des Dichters

Lasst uns besser werden Gleich wird's besser sein.

Wir hoffen daher, die Arztrereine werden denen nicht beistimmen, die die Alsweisung des Entwurfes a limine verlangen. Sie werden die Sätze der Ninimaltaxe ruligg prüfen, ohne Vorurtheil der gerechten Forderungen des eigenen Standes gedenkend, aber aucl der Pflichten desselben. Möchten sie doch aus den anerkenuenswerthen Vorgehen des Ministers noch eine wichtige Folgerungr ziehen. Die Aufstellungr einer Minimaltaxe bringt thatsäcllich den Erweis. dass die Aerzte nicht reine Gewerbetreibende sind, dass man ihnen Pflichten gegen die Gesanmtheit um dieser selbst auferlegen unuss, die von den reinen Gewerbetreibenden niemals verlangt werden. Die Linhaltbarkeit der gegen wärtigen Halblıeit, Jängst erkannt und schon durch die in Angriff genommene Organisation unseres Standes officiell festgestellt, wird damit notorisch und der Staat wird sich der ihm obliegenden Gcgenleistung nicht entziehen. Constatirt der Minister mit dem Entwurf der Minimaltaxe im Interesse der Gesamıtheit thatsächlich, dass wir bine reinen Gewerbetreibenden sind, so können wir an ihn in demselben Interesse, nicht nur in dem unseren, das wohberechtigte Ansuchen stellen, dahin seinen Einfluss zu richten, dass die Freilıeit der nedicinischen Pfuscherei ein Ende nehne. Mögen gerade jetzt die Arztvereine dies erwägen.

P. Börner.

\section{Zur Orientirung über den neuen Taxentwurf.} Die Aerzte in Preussen haben es dankbar anerliannt, dass sicl Minister Falk, getreu seinen auf anderen Gebieten längst bewährten Grundsätzen, in allen sie interessirenden grösseren Fragen zweifellos dahin entschieden laat, ihre Stimme zu lıören. Seinen Intentionen gemäss beschäftigen sich, wie uns berichtet wird, schon zahlreiche Arztvereine mit dem in seinen Ministerien ausgearbeiteten Entwurfe einer Mininaltaxe und so mögen denn einige Beınerkungen aucl unsererseits ilıre Stelle finden.

Es landelt siclı unseres Ermessens vor Allem um die Feststellung des Princips, von welchem der Minister ausgegangen ist. Wir glauben dasselbe 